\title{
Analysis of Water Barrier, Mechanical and Thermal Properties of Nanocoposites Based on Cassava Starch and Natural Clay or Modified by Anionic Exchange
}

\author{
Mayra Kerolly Sales Monteiro ${ }^{a}$, Victor Rafael Leal de Oliveira ${ }^{b *}$, Francisco Klebson Gomes dos \\ Santos $^{b}$, Ricardo Henrique de Lima Leite ${ }^{b}$, Edna Maria Mendes Aroucha ${ }^{b}$, Rayane Ricardo da Silva, \\ Karyn Nathallye de Oliveira Silva ${ }^{a}$ \\ a Universidade Federal do Rio Grande do Norte - UFRN, Natal, RN, Brazil \\ ${ }^{b}$ Universidade Federal Rural do Semi-Árido - UFERSA, Mossoró, RN, Brazil
}

Received: December 14, 2016; Revised: February 20, 2017; Accepted: April 9, 2017

\begin{abstract}
Biopolymer films have several industrial applications because they are environmentally sustainable. Cassava starch is a biopolymer that is easily available, but has limitations: it is hydrophilic, poorly resistant and degradable. The improvement of these properties was proposed in this research from the use of bentonite clay (BT) as a filling material. The compatibilization of this in the polymer matrix was obtained by ion exchange with an organic anionic surfactant. The formation of intercalated or exfoliated starch nanocomposites in the presence of natural or modified clay was characterized by XRD, FTIR, AFM and SEM. The improvement of water vapor, thermal and mechanical properties was investigated by WVP, solubility, TGA and tensile test. The starch nanocomposites in the presence of modified clay showed a better result than those of natural clay. There was no significant difference in the color of the starch film in the presence of the natural or modified clay.
\end{abstract}

Keywords: Nanocomposite, Starch, Bentonite clay, Ion exchange

\section{Introduction}

Biopolymer nanocomposites that use natural clay as a filling material have been the focus of academic and industrial attention in recent years because composites formed often exhibit a desired improvement in water vapor barrier, mechanical and thermal properties relative to the original biopolymer matrix ${ }^{1}$. The improvement is directly related to the dispersion of the clay layers in the biopolymer matrix, which in turn depends on the intensity of the interfacial interactions between the biopolymer structure and the silicate layers (organically modified or not) ${ }^{2}$.

The simple mixing of biopolymer and clay does not always result in the generation of an ideal nanocomposite. This failure is due to the weak interactions between the hydrophilic biopolymer and the natural hydrophilic clay, resulting in an intercalated dispersion of the filling material in the biopolymer matrix ${ }^{3}$. In turn, the natural clay shows counter-ions on the intercalated surface of the silicate layers, this counter-ions may be the result of the presence of solvents such as ethylene glycol and ethyl alcohol, depending on the case, and these are responsible for the swelling of the clay in water which favors the ion exchange reaction with organic modifiers through hydrogen bonds ${ }^{4,5}$.

The function of the organic modifier is primarily to broaden the basal spacing between the silicate layers of

* e-mail: vrafaeloliveira@uol.com.br the clay, creating space for the biopolymer to penetrate between the lamellar galleries during the formation of the nanocomposite. Therefore, the complete compatibility between the long chain organic modifier and the biopolymer matrix may be preferable for a better dispersion of the clay, as it provides the formation of exfoliated nanocomposites with improved properties.

In addition, cassava starch is a thermoplastic biopolymer matrix of low cost and easy to obtain, however it is composed of amylose (16-24\%) and amylopectin (84-76\%) constituents responsible for the low water vapor barrier, mechanical and thermal properties ${ }^{7}$. The aim of this work was to characterize and determine the improvement of water vapor barrier, mechanical and thermal properties of cassava starch films due to the presence of the modified clay with an organic anionic surfactant.

\section{Materials and Methods}

\subsection{Materials and reagents}

Cassava starch was supplied by the Industria Primicias do Brasil (Macaiba, Rio Grande do Norte, Brazil). Sodium bentonite clay was purchased by Armil Mineração Nordeste - AMN (Parelhas, Rio Grande do Norte, Brazil), with a light cream color, in powder form, with a mean particle size of 0.074 $\mathrm{mm}$ and ion exchange capacity of $75 \mathrm{meq} / 100 \mathrm{~g}$. The sodium dodecyl sulfate (SDS) was the organic anionic surfactant 
used, manufactured at Inlab Confiança (São Paulo, Brazil). Ethylene glycol (Merck KGaA) manufactured by Darmstadt, (Germany), with molar mass of $62.07 \mathrm{~g} / \mathrm{mol}$ and $99.5 \%$ purity was used. Glycerin, used as plasticizer, was purchased from Chemical Dynamics Inc. Contemporary (Brazil).

\subsection{Anionic Exchange}

According to the methodology of LI \& $\mathrm{GUO}^{8}$, a BT clay solution was prepared dissolving $0.25 \mathrm{~g}$ of BT clay in 80 $\mathrm{ml}$ of ethylene glycol (Solution 1), under uniform stirring. Then, $1 \mathrm{~g}$ of SDS was dissolved in $20 \mathrm{ml}$ of distilled water and then mixed with Solution 1. For complete uniformity, the mixture was stirred at $1000 \mathrm{rpm}$. The $\mathrm{pH}$ value of the blend was adjusted to 4.7 by $0.1 \mathrm{~mol} / \mathrm{L} \mathrm{HNO}_{3}$ solution and then reacted at $100^{\circ} \mathrm{C}$ for two hours. The solution was then cooled, washed and filtered. The reaction product was dried in vacuo at $80^{\circ} \mathrm{C}$ and then grinded to obtain the modified BT-SDS clay.

\subsection{Preparation of starch / clay nanocomposite}

The film was prepared according to the methodology proposed by Cyras et al ${ }^{9}$. A solution of $70 \mathrm{ml}$ containing $5 \%$ $(\mathrm{w} / \mathrm{v})$ cassava starch was prepared. Glycerin was added in a starch-plasticizer weight ratio of 1: 0.3 , the percentage of cassava starch is in relation to $100 \mathrm{ml}$ of final film-forming solution. The mixture was heated at $70^{\circ} \mathrm{C}$ for $15 \mathrm{~min}$ until complete homogenization. Then, two different solutions dispersed in distilled water were prepared: natural BT clay and anionic BT clay. The mixtures were placed in an ultrasonic bath at room temperature, $25^{\circ} \mathrm{C}$. The starch solution and the clay mixtures were homogenized, forming the final film solution, and finally placed in an ultrasonic bath for 30 minutes to facilitate dissolution. The film-forming solutions were prepared by adding $5 \%$ by weight of bentonite clay to the dry mass of biopolymer and then arranged in rectangular plates and dried at $40^{\circ} \mathrm{C}$ for 6 hours.

\subsection{Characterizations}

\subsubsection{Visual aspect}

In this stage, the biofilms that showed the best visual aspects, absence of cracks or areas with tendency to rupture, without insoluble particles and uniform color were selected.

\subsubsection{Thickness}

The film thickness was measured with a micrometer (Mitutoyo, model MDC-25M/ Japan) with sensitivity of $0.001 \mathrm{~mm}$. Five thickness measurements were carried out on each film.

\subsubsection{Fourier transform infrared spectroscopy - FTIR}

The FTIR analyzes were performed on a Shimadzu spectrometer, with a scan of $4000-500 \mathrm{~cm}^{-1}$.

\subsubsection{X-ray diffraction - XRD}

The x-ray diffraction analyses were performed on a Shimadzu (model XRD-6000), at angles between $2 \Theta$ from $1.5^{\circ}$ to $40^{\circ}$ and a scanning speed of $2^{\circ} / \mathrm{min}$.

\subsubsection{Scanning electronic microcopy - SEM}

The samples were submitted to the SEM (model VEGA 3 TM, TESCAN-Czech Republic, 2013) applied at a voltage of $15 \mathrm{KV}$, with a magnitude of $1 \mathrm{Kx}$.

\subsubsection{Atomic Force Microscopy - AFM}

The morphological surface of the films was analyzed using a Shimadzu (model SPM-9700). The analysis was performed in dynamic mode (tapping mode) with a scanning speed of $1 \mathrm{~Hz}$. No treatment was done on the sample for analysis.

\subsubsection{Thermogravimetric analysis - TGA}

The analysis of films was performed using a Shimadzu (model DTG - 60). Data were collected on samples of $5 \mathrm{mg}$ during a ramp temperature from $25^{\circ} \mathrm{C}$ to $600^{\circ} \mathrm{C}$ at $10^{\circ} \mathrm{C} / \mathrm{min}$ under a nitrogen flux of $100 \mathrm{ml} / \mathrm{min}$.

\subsubsection{Water vapor permeability - WVP}

The water vapor permeability of the films was determined gravimetrically, according to the standard ASTM method E96-95 ${ }^{10}$, with slight modification. The films were cut into square pieces $(2 \mathrm{~cm} \times 2 \mathrm{~cm})$ and sequentially deposited on top of the WVP measuring cells. The water level was up to $1 \mathrm{~cm}$ below the film. The weight of each cell was measured before being deposited in a desiccator which contained silica stones at the bottom, as well as a relative humidity of $50 \%$ and internal temperature of $29^{\circ} \mathrm{C}$. Cell weight was measured every hour over a period of $8 \mathrm{~h}$. The WVP of the films was calculated in $\mathrm{g} / \mathrm{m}$.s.Pa as follows in Equation 1:

$$
W V P=\frac{W \cdot L}{A \cdot t . \Delta P}
$$

Where $\mathrm{W}$ is the weight of water permeating through the film (g); $\mathrm{L}$ is the film thickness (m); $\mathrm{A}$ is the permeation area $\left(\mathrm{m}^{2}\right) ; \mathrm{t}$ is //the permeation time $(\mathrm{s}) ; \Delta \mathrm{P}$ is the pressure difference to water vapor between the two sides of the film $(\mathrm{Pa})$. 


\subsubsection{Solubility}

For solubility, the methodology adapted from $\mathrm{Ge}$ et $\mathrm{al}^{11}$ was used. Film disks with $2 \mathrm{~cm}$ of diameters were dried at $105^{\circ} \mathrm{C}$ for $1 \mathrm{~h}$. The disks were immersed in distilled water at room temperature, shaken for 24 hours. Then the they were dried again at $105^{\circ} \mathrm{C}$ for $1 \mathrm{~h}$. The solubility was calculated from Equation 2:

$$
S=\frac{m i-m f}{m i} \chi 100
$$

Where $\mathrm{S}$ is the solubility (\%); $\mathrm{m}_{\mathrm{i}}$ is the initial mass $(\mathrm{g})$; $\mathrm{m}_{\mathrm{f}}$ is the final mass $(\mathrm{g})$.

\subsubsection{Opacity}

The opacity of the films was determined by the colorimeter (model CR 10, Minolta), calibrated with a standard white background and a standard black background. The opacity values were calculated according to Equation $3^{12}$ :

$$
\mathrm{O} p=\frac{\mathrm{O} p B}{\mathrm{O} p w} \varkappa 100
$$

Where $\mathrm{Op}_{\mathrm{B}}$ is the opacity of the film against a black background; $\mathrm{Op}_{\mathrm{w}}$ is the opacity of the film against a white background.

\subsubsection{Mechanical properties}

The mechanical properties were determined using an Testing Machine (model DL5000/10000, Paraná, Brazil), which operates according to standard ASTM method D882-83 12 at a test speed of $5 \mathrm{~mm} / \mathrm{min}$ with application of total force of $5 \mathrm{KN}$. The samples follow the same standard and are evaluated with length of $50 \mathrm{~mm}$, width of $5 \mathrm{~mm}$ and maximum thickness of $0.25 \mathrm{~mm}$.

\subsubsection{Statistical analysis}

All data were collected at least in triplicate. The significant difference between averages was established by the Duncan method with a level of statistical significance lower than 5\%.

\section{Results and Discussion}

\subsection{Mechanism of formation of starch-natural or modified clay nanocomposites}

Figure 1 adapted from CHIU et $\mathrm{al}^{2}$, illustrates the proposed mechanism for the formation of starch and natural or modified clay nanocomposites.

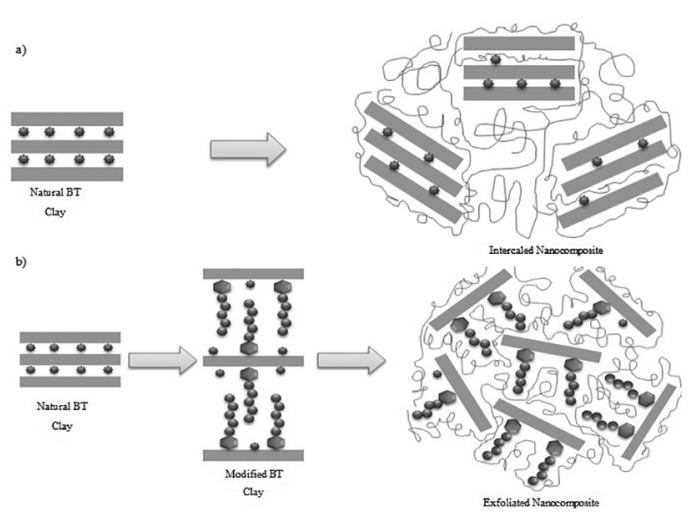

Figure 1. Mechanism of starch-clay nanocomposites: a) Intercalated and b) Exfoliated.

Figure 1 (a) shows initially that the BT clay has a stacked silicate layer structure, interconnected by an interlamellar spacing in the presence of inorganic ions, responsible for stabilizing the negative structure of the BT clay and making it hydrophilic ${ }^{2}$. In the formation of the nanocomposite the bentonite clay is used as a filling material in a cassava starch matrix. Cassava starch is basically composed of thousands of glucose monomers interconnected by alpha glycosidic bonds. These monomers are derived from the amylose and amylopectin structure, consisting of hydrocarbons $(-\mathrm{CH})$ and hydroxyl groups (-OH) along branched chains ${ }^{7}$. Due to its structure the cassava starch is highly hydrophilic and therefore has low affinity with natural BT clay. An intercalated nanocomposite is formed where the stacked clay structure does not completely interact with the biopolymer matrix. Figure 1 (b) shows that the BT clay before forming the nanocomposite has on its surface interlamellar counter-ions that interact with sodium dodecyl sulfate, an organic anionic surfactant. The chemical modification on the interlamellar surface of the clay due to the presence of the organic surfactant provides an increase in the basal distance between the silicate layers, facilitating the intercalation of the biopolymer ${ }^{3}$. The functional groups of the surfactant cause bigger affinity with the structure of the biopolymer matrix, resulting in the formation of an exfoliated nanocomposite ${ }^{1}$.

\section{Characterization of Starch-Clay Nanocomposites}

\subsection{X-ray diffraction - XRD}

X-ray diffraction analyzes were performed on the composite materials in order to investigate the dispersion of the silicate layers. Figure 2 shows the XRD patterns obtained for the starch film and for the nanocomposites of starch and natural or modified clay.

The characteristic peak identified in $2 \theta=12^{\circ}$, corresponding to the crystalline plane (002), in figure 2 , refers to the compound $\mathrm{Si}_{2} \mathrm{Al}_{2} \mathrm{O}_{5}(\mathrm{OH})_{4}$, thus confirming the presence 


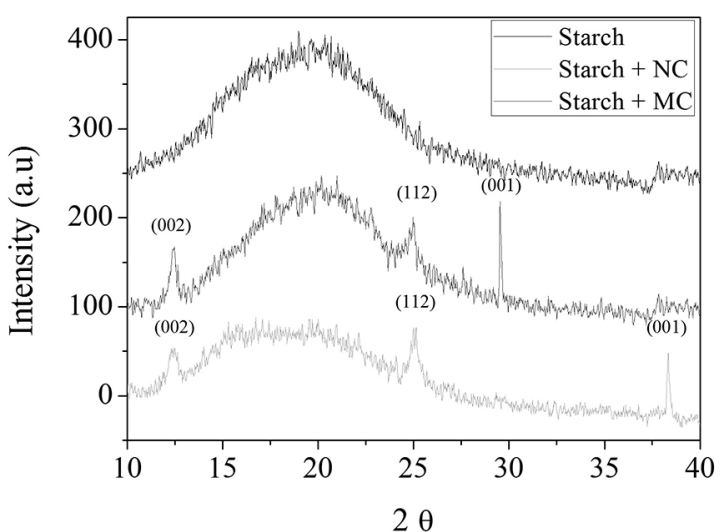

Figure 2. X-ray diffraction for starch and for the starch and natural or modified clay nanocomposites.

of BT clay in the cassava starch-based nanocomposites; the compound is kaolinite, one of the clay minerals that compose the bentonite, with crystalline structure which reflects a tetrahedral blade of silica bound to an octahedral blade of alumina ${ }^{2}$.

Still in figure 2 shows that the standard film diffractogram of the starch and natural clay nanocomposites differs from that of the starch film due to the appearance of characteristic peaks, such as around $2 \theta=38^{\circ}$ corresponding to the crystalline plane (001), which according to MANFREDI et $\mathrm{al}^{14}$, this peak refers to the presence of the elements that compose the crystalline structure of the silicate layers of the BT clay displaced to values of higher diffraction angles, this may prove that the interlamellar region of the clay was expanded during the formation of the nanocomposite providing an intermediate dispersion along the starch matrix. Moreover, the standard diffractogram of nanocomposites of starch and modified clay showed the same peak, but at a diffraction angle lower than that observed by the presence of the natural clay, around $2 \theta$ $=28^{\circ}$, this displacement according to GIANNAKAS et al ${ }^{15}$ can be explained by the modification of the interlamellar surface that increases the basal distance between the silicate layers, providing space to the biopolymer interact with the functional groups of the anionic surfactant, resulting in compatibility between them in the exfoliation of the silicate layers along the starch matrix.

\subsection{Fourier transform infrared spectroscopy - FTIR}

The analyses were carried out to investigate the potential interactions between cassava starch and natural or modified clay. The FTIR spectra of the starch films and the nanocomposites of starch and natural or modified clay in the range of $3600-2800 \mathrm{~cm}^{-1}$ are given in Figure 3.

Figure 3 shows the appearance of bands related to the asymmetric stretching of the common $\left(-\mathrm{CH}_{2}^{-}\right)$hydrocarbon bonds in the three samples at $2900 \mathrm{~cm}^{-1}$, as well as the

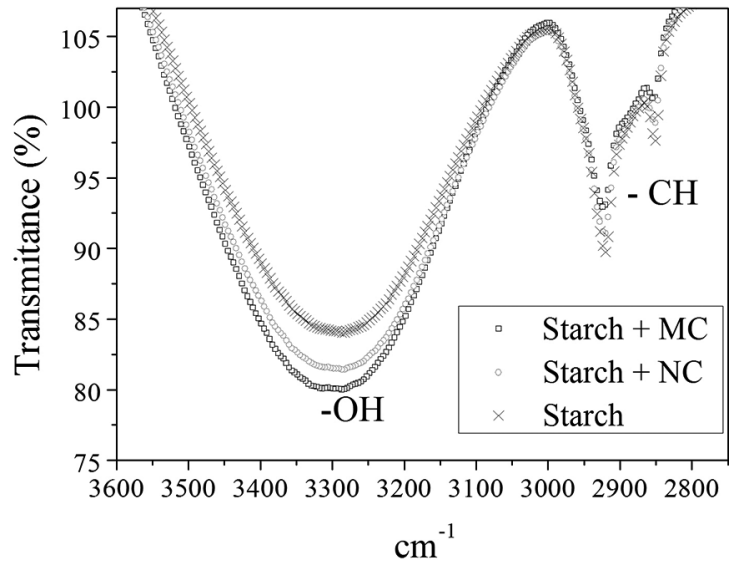

Figure 3. Spectra in the infrared region for the starch film and for the nanocomposites of starch and natural or modified clay.

appearance of elongated bands at $3300 \mathrm{~cm}^{-1}$ corresponding to the stretching of the bonding of the groups $(-\mathrm{OH})$, however, in the last case it was possible to notice that there was a distinction in the three transmittance bands, which may be associated with the number of hydrogen bonds established in each case ${ }^{16,17}$. Thus, the greater the elongation of the transmittance band, the greater the number of hydrogen bonds established in the film. In fact, the layers that form the stacked structure of the BT clay have a three-dimensional crystalline structure with an octahedral sheets in the center of two tetrahedral sheets, this structure results in the presence of hydroxyl groups on the surface of the clay stabilized by the presence of free sodium cations in the interlamellar galleries, this fact does not favor the complete aggregation of the clay in the hydrophilic starch structure ${ }^{2,4}$, but this may prove the greater appearance of hydrogen bonds due to the lower presence of the free hydroxyl groups in the starch and natural clay film bands in relation to the pure starch film. In turn, the starch and modified clay nanocomposites contained the highest amount of hydrogen bonds established by the lower presence of free hydroxyl groups in relation to the other two biofilms, proving the electrostatic affinity of the functional groups of the surfactant with the structure of cassava starch.

\subsection{Atomic Force Microscopy - AFM}

The atomic interaction between the constituents of the nanocomposites could be investigated through the topographic study of the films surface established by the AFM as shown in Figure 4.

As shown in Figure 4 (a), there are significant depressions that reflect the lack of homogeneity along the surface of the starch films ${ }^{7}$. In turn, the starch in the presence of the natural clay as a filling material (Figure 4 (b)), presents a substantial improvement, this may be due to the possible interaction of the natural clay with the starch matrix in an 


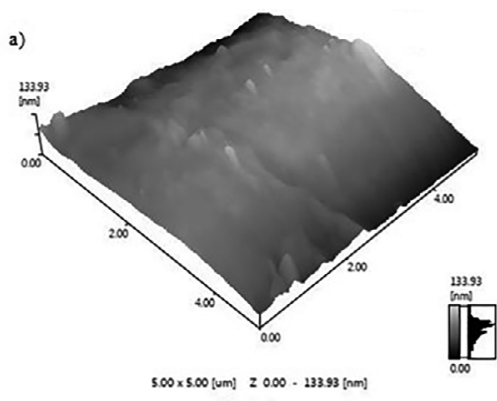

Feculs-Sum

c)

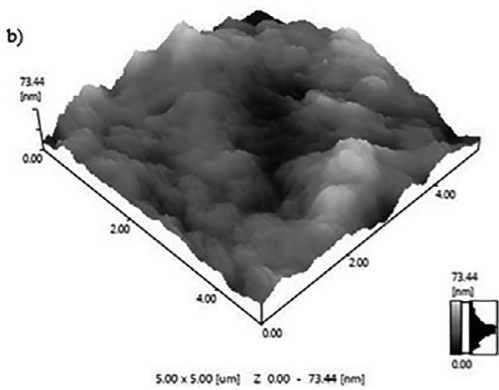

notural_sum

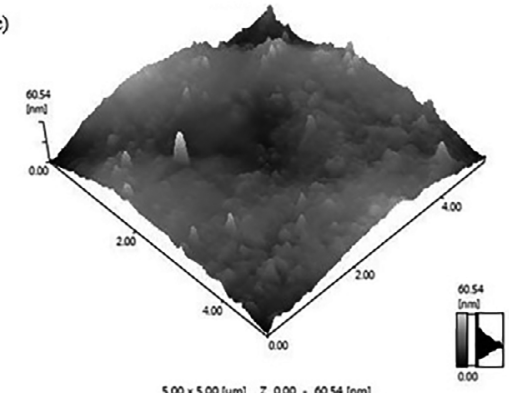

$5.00 \times 5.00[\mathrm{Um}] z 20.00-00.54[\mathrm{~nm}]$

AN-5\%_Sum

Figure 4. Atomic force micrograph showing the surface topography on films of: a) Starch, b) Starch-natural clay and c) Starch- modified clay.

intercalary form ${ }^{18}$, the starch nanocomposite in the presence of the modified clay (Figure 4 (c)), shows had a reduction in the roughness, resulting in an exfoliated and homogeneous material ${ }^{19}$, corroborating with the images of the morphological analyzes of SEM, demonstrating, respectively, the linearity in the homogeneity behavior of the films produced. The SEM analyzes are reported in Figure 5 (a), (b), (c), respectively. These results confirm the evidence in FTIR.

\subsection{Scanning electronic microcopy - SEM}

SEM analyzes of starch and natural or modified clay nanocomposites are shown in Figure 5. SEM is used to visualize the pattern of arrangement of dispersed silicate layers through the biopolymer matrix before and after modification.

Figure 5 (a) shows a disorganized biopolymer structure, which may be explained by the fact that the cassava starch has a structure interlaced between the amylose and amylopectin molecules by hydrogen bonds forming radially ordered crystalline areas. Among these crystalline areas there are amorphous regions, in which the molecules have no particular orientation. In turn, it is in these crystalline areas that the aggregation of the plasticizer occurs in the thermoplastic process, responsible for reducing intermolecular forces and increasing the mobility of the biopolymer chain ${ }^{6}$. Figure 5 (b) shows visually that the starch and natural clay nanocomposites formed agglomerates along the biopolymer matrix due to the lack of affinity between the structures of the starch and the natural clay, in which case the silicate layers remain stacked, not allowing a larger interaction with the biopolymer matrix forming an intercalated nanocomposite ${ }^{24}$. Figure 5 (c) shows that the nanocomposites of starch and modified clay form a cohesive biopolymer matrix, because the clay is in this case organically modified with an organic surfactant
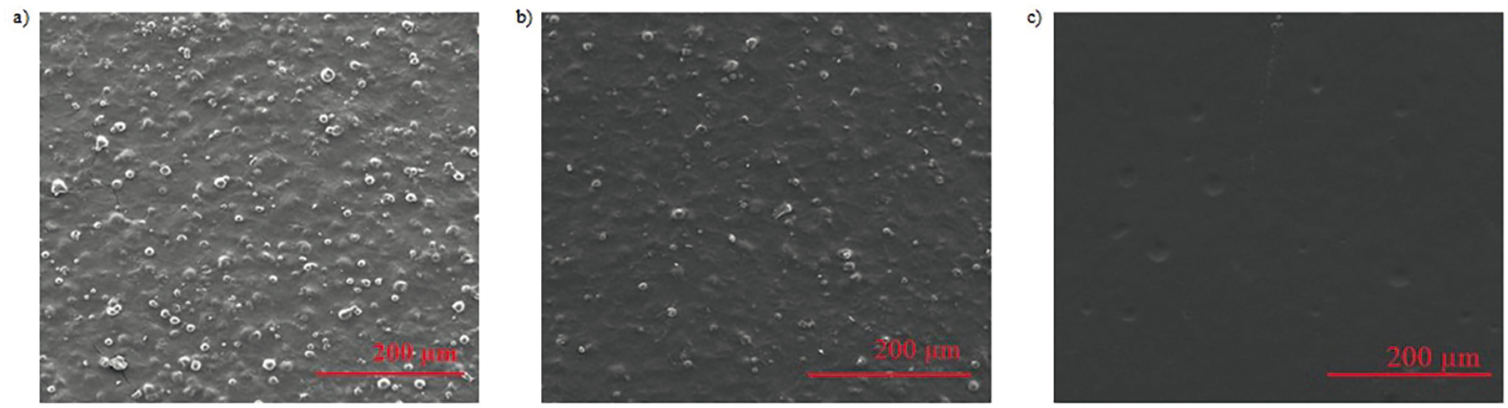

Figure 5. Analyzes made in a scanning electron microscope on the nanocomposites: a) cassava starch, b) starch- natural clay and c) starch- modified clay. Magnification: 300x. 
that allows the penetration of the biopolymer, compatible electrostatically with the functional groups of the surfactant, between the silicate layers making possible a better dispersion of the clay along the biopolymer matrix and characterizing the formation of an exfoliated nanocomposite ${ }^{26}$. The results were satisfactorily correlated with that obtained by AFM.

\subsection{Thermogravimetric analysis - TGA}

Thermal analysis was performed to determine if the addition of modified BT clay produced any change in the thermal decomposition behavior of cassava starch. Figure 6 shows the behavior of three thermogravimetric curves related to the mass loss of starch film and the starch and natural or modified clay nanocomposites.

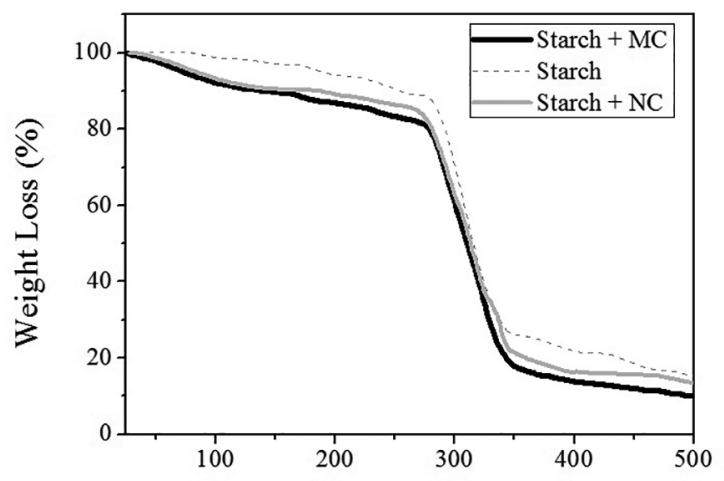

Figure 6. Thermogravimetric curves for the starch film and for the nanocomposites of starch and natural or modified clay.

The cassava starch film and the nanocomposites of starch and natural or modified clay were subjected to a temperature range between $25^{\circ} \mathrm{C}$ and $500^{\circ} \mathrm{C}$. In this condition, in each case two steps were observed through the curve formed by mass loss. The first stage corresponds to the evaporation of the water adsorbed by the starch and the filling material, where for the starch films this stage is between $25^{\circ} \mathrm{C}$ and $287^{\circ} \mathrm{C}$, being between $25^{\circ} \mathrm{C}$ and $262.5^{\circ} \mathrm{C}$ for the nanocomposites of starch and natural clay and between $25^{\circ} \mathrm{C}$ And $252^{\circ} \mathrm{C}$ for the starch and modified clay nanocomposites. The second step refers to the decomposition point of the cassava starch that was given from $337.5^{\circ} \mathrm{C}$ for the pure starch films, $350^{\circ} \mathrm{C}$ for the starch and natural clay nanocomposites and $362^{\circ} \mathrm{C}$ for the starch and modified clay nanocomposites, similar results were observed by Lee et al. (2014) $)^{15}$ and Qi et al. (2016) ${ }^{18}$. In fact, the presence of modified BT clay gives the starch film a greater loss of mass, around $18 \%$ in relation to pure starch and $7 \%$ in relation to the biofilm in the presence of natural BT clay, as well as retardation the point of decomposition of the same. This may be due to the BT clay when modified with the presence of an organic anionic surfactant, to cause a greater interaction with the biopolymer matrix as evidenced by the FTIR and AFM analyzes, and therefore to act as a heat barrier to the which is more effective when compared to natural clay, thus being responsible for a marked improvement in the thermal stability of the starch matrix ${ }^{14}$.

\subsection{Water vapor permeability, Solubility e Opacity}

Table 1 shows the influence of the presence of natural or modified clay on cassava starch films in properties improvement of the original film through the results of water vapor permeability, solubility and opacity.

The light transmission in the starch films decreased with the presence of the filling material as shown in Table 1. The opacity values of the starch and natural or modified clay nanocomposites did not differ significantly from the value showed by the starch film and could be considered transparent. The starch film showed $43.13 \%$ opacity and this increased to $43.49 \%$ with the addition of modified clay or $45.53 \%$ with the addition of natural clay. The modified clay nanocomposite gave to the cassava starch matrix a lower opacity when compared to the natural clay nanocomposite, this may be related to the fact that the modified clay is dispersed for all biopolymer matrix uniformly and in a suitable portion ( $5 \%$ in relation to the dry mass of the polymer), thus not influencing the opacity of the nanocomposite ${ }^{18}$. The higher reduction in light transmission of starch and natural clay nanocomposites suggests that natural clay was not completely dispersed by forming intercalated agglomerations in the matrix of the biopolymer, preventing the passage of light through the film ${ }^{16,23}$. This discussion is according to the one characterized in the XRD.

Table 1 also shows the decrease in solubility of cassava starch films with the presence of natural or modified clay, this may be due to the volume of the biopolymer matrix being reduced by the interaction with the filling material during formation of the nanocomposite ${ }^{22,25}$. Such interaction also causes a decrease in water vapor permeability because a tortuous path is formed for the diffusion molecules ${ }^{28}$. The presence of the modified clay in the starch film reduced

Table 1. Shows the effect of the presence of natural or modified clay on starch films on: (a) water vapor permeability, (b) solubility and (c) opacity. Different letters indicate the statistical difference $(p<0.05)$.

\begin{tabular}{lccc}
\hline & WVP $\left(\times 10^{-2} \mathrm{~g} / \mathrm{m}\right.$. Pa.s $)$ & Solubility (\%) & Opacity (\%) \\
\hline Starch & $3.4737 \pm 0.0932^{\mathrm{a}}$ & $73.28 \pm 0.9277^{\mathrm{a}}$ & $43.13 \pm 0.05^{\mathrm{a}}$ \\
Starch + NC & $2.8832 \pm 0.0771^{\mathrm{b}}$ & $63.75 \pm 0.7509^{\mathrm{b}}$ & $45.47 \pm 0.09^{\mathrm{a}}$ \\
Starch + MC & $1.9105 \pm 0.0655^{\mathrm{c}}$ & $51.29 \pm 0.9084^{\mathrm{c}}$ & $43.49 \pm 0.06^{\mathrm{a}}$ \\
\hline
\end{tabular}


the WVP by $45 \%$ and the solubility by $30 \%$. On the other hand, the natural clay reduced the WVP of the starch films around $17 \%$ and of $13 \%$ the solubility. The improvement in the barrier property was better in the WVP than in the solubility because the reduction of the diffusion coefficient was greater than the solubility coefficient ${ }^{27}$. In fact, the clay volume fraction is low and therefore the matrix volume reduction is small. The main factor, then, is the tortuosity, which is directly connected with the degree of dispersion of the clays. The degree of dispersion of the clays is determined by their degree of exfoliation ${ }^{28}$. Therefore, as the starch and modified clay exfoliated nanocomposite presents higher values for the tortuosity factor, in comparison to the intercalated nanocomposite of starch and natural clay, it becomes more effective its use as membranes of water vapor barrier ${ }^{27}$. These results are in accordance with the characterized in FTIR and AFM.

\subsection{Mechanical Properties}

The influence of the presence of natural or modified BT clay on improvement of the mechanical properties of starch films was investigated. The results of the deformation, elasticity and tensile strength through the tensile test on cassava starch films are shown in Table 2.

Table 2. Shows the mechanical properties analysis of starch films $(0 \%)$, starch and natural clay nanocomposites (NM5\%) and starch and modified clay nanocomposites (M5\%) through: a) Deformation, b) Elasticity and c) Tensile strength.

\begin{tabular}{lccc}
\hline & $\begin{array}{c}\text { Deformation } \\
(\mathrm{mm})\end{array}$ & $\begin{array}{c}\text { Elasticity } \\
(\mathrm{MPa})\end{array}$ & $\begin{array}{c}\text { Tensile } \\
\text { strength } \\
(\mathrm{MPa})\end{array}$ \\
\hline Starch & $69.09 \pm 0.6418^{\mathrm{a}}$ & $13.5 \pm 0.82^{\mathrm{a}}$ & $3.2 \pm 0.6^{\mathrm{a}}$ \\
Starch + NC & $58.81 \pm 0.5216^{\mathrm{a}}$ & $48.5 \pm 0.63^{\mathrm{b}}$ & $6.4 \pm 0.77^{\mathrm{a}}$ \\
Starch +MC & $47.75 \pm 0.6789^{\mathrm{b}}$ & $63.77 \pm 0.525^{\mathrm{c}}$ & $9.3 \pm 0.41^{\mathrm{b}}$ \\
\hline
\end{tabular}

Table 2 shows the results for mechanical properties analysis of the cassava starch films according to the presence of the natural or modified clay. In general, the addition of BT clay as a filling material increased the tensile strength and elasticity of the cassava starch films and reduced their deformation capacity, as observed by Cyras et al (2008) ${ }^{7}$, Navarchian et al $(2010)^{20}$, Matsuda et al $(2014)^{26}$, Farahnaky et al $(2014)^{16}$, Liao et al $(2015)^{3}$ e Romero-Bastida et al (2015) ${ }^{29}$. Modified clay nanocomposites showed a better result when compared to natural clay based biofilms. This can be due to the exfoliated structure showed by the nanocomposite formed in the presence of the modified clay, to improve the results obtained during the transport of the tension applied by the best dispersion of the reinforcing elements ${ }^{29}$. On the other hand, the nanocomposites based on natural clay show an improvement in comparison to the starch film due to the formation of intercalated and aggregated tactoids in the biopolymer matrix evidenced in the intercalated structure observed in SEM, so it can act as a nucleating agent resisting stretching of the main chain interconnected with the biopolymer matrix by hydrogen bonding ${ }^{7}$. Moreover, the deformation values decreased with the increase of the natural or modified BT clay concentration, and this effect was higher in the modified clay based nanocomposites. This can be attributed to the fact that the filling materials in this case decrease the deformation of the polymer structure due to the formation of an immobilizing biopolymer layer at the polymer/filling material interface ${ }^{30}$.

\section{Conclusion}

It was investigated the improvement of water vapor barrier, mechanical and thermal properties of the cassava starch films with the addition of natural or modified clay. The natural clay did not present compatibility to the starch film, resulting in the formation of an intercalated nanocomposite, whereas the modified clay gave rise to the formation of a exfoliated nanocomposite, both situations being characterized by XRD, FTIR, AFM and SEM. In the TGA, it was possible to analyze that the nanocomposites based on modified clay contributed more effectively to the improvement of the thermal stability of the starch. The mechanical analysis, in general, showed that BT clay increased tensile strength and elasticity, and decreased the deformation capacity of cassava starch films, and the presence of modified clay showed the best result. The nanocomposite of starch and modified clay was considered the best membrane of water vapor barrier, showing the lowest water vapor permeability. The transparency values of starch and natural or modified clay nanocomposites did not differ significantly from the value presented by the starch film and can be considered transparent.

\section{Acknowledgments}

Authors thank to Laboratory of Chemical Processes (UFERSA); to Food Technology Laboratory (UFERSA); to Laboratory of Nanostructured Materials and Catalytic Reactors - LAMNRC (UFRN); to Laboratory of Structural Characterization of Materials (UFRN); To Nucleus of Education and Research in Oil and Gas - NUPEG (UFRN) and to Conselho Nacional de Desenvolvimento Cientifico e Tecnologico (CNPQ) for their financial support.

\section{References}

1. Pavlidou S, Papaspyrides CD. A review on polymer-layered silicate nanocomposites. Progress in Polymer Science. 2008;33(12):1119-1198.

2. Chiu CW, Huang TK, Wang YC, Alamani BG, Lin JJ. Intercalation strategies in clay/polymer hybrids. Progress in Polymer Science. 2014;39(3):443-485. 
3. Liao X, Ren L, Chen D, Liu X, Zhang H. Nanocomposite membranes based on quaternized polysulfone and functionalized montmorillonite for anion-exchange membranes. Journal of Power Sources. 2015;286:258-263.

4. Kotal M, Bhowmick AK. Polymer nanocomposites from modified clays: Recent advances and challenges. Progress in Polymer Science. 2015;5:127-187.

5. Tang X, Alavi S, Herald TJ. Effects of plasticizers on the structure and properties of starch-clay nanocomposite films. Carbohydrate Polymers. 2008;74(3):552-558.

6. Chiu CW, Lin JJ. Self-assembly behavior of polymer-assisted clays. Progress in Polymer Science. 2012;37(3):406-444.

7. Zhu F. Composition, structure, physicochemical properties, and modifications of cassava starch. Carbohydrate Polymers. 2015;122:456-480.

8. Li M, Guo Q. The preparation of the hydrotalcite-based composite phase change Material. Applied Energy. 2015;156:207-212.

9. Cyras VP, Manfredi LB, Ton-That MT, Vázquez A. Physical and mechanical properties of thermoplastic starch/montmorillonite nanocomposite films. Carbohydrate Polymers. 2008;73(1):55-63.

10. Shankar S, Teng X, Li G, Rhim JW. Preparation, characterization, and antimicrobial activity of gelatin/ZnO nanocomposite films. Food Hydrocolloids. 2015;45:264-271.

11. Ge L, Li X, Zhang R, Yang T, Ye X, Li D, et al. Development and characterization of dialdehyde xanthan gum crosslinked gelatin based edible films incorporated with amino-functionalized montmorillonite. Food Hydrocolloids. 2015;51:129-135.

12. Fakhouri FM, Martelli SM, Caon T, Velasco JI, Mei LHI. Edible films and coatings based on starch/gelatin: Film properties and effect of coatings on quality of refrigerated Red Crimson grapes. Postharvest Biology and Technology. 2015;109:57-64.

13. ASTM International. ASTM D882 - Standard Test Method for Tensile Properties of Thin Plastic Sheeting. West Conshohocken: ASTM International; 2012.

14. D'Amico DA, Manfredi LB, Cyras VP. Crystallization behavior of poly(3-hydroxybutyrate) nanocomposites based on modified clays: Effect of organic modifiers. Thermochimica Acta. 2012;544:47-53.

15. Giannakas A, Spanos CG, Kourkoumelis N, Vaimakis T, Ladavos A. Preparation, characterization and water barrier properties of PS/organo-montmorillonite nanocomposites. European Polymer Journal. 2008;44(12):3915-3921.

16. Farahnaky A, Dadfar SMM, Shahbazi M. Physical and mechanical properties of gelatin-clay nanocomposite. Journal of Food Engineering. 2014;122:78-83.

17. Liu H, Chaudhary D, Yusa SI, Tadé MO. Glycerol/starch/ $\mathrm{Na}^{+}$montmorillonite nanocomposites: A XRD, FTIR, DSC and ${ }^{1} \mathrm{H}$ NMR study. Carbohydrate Polymers. 2011;83(4):1591-1597.
18. Flaker CHC, Lourenço RV, Bittante AMQB, Sobral PJA. Gelatin-based nanocomposite films: A study on montmorillonite dispersion methods and concentration. Journal of Food Engineering. 2015;167(Pt A):65-70.

19. Qi G, Li N, Sun XS, Shi YC, Wang D. Effects of glycerol and nanoclay on physiochemical properties of camelina gum-based films. Carbohydrate Polymers. 2016;152:747-754.

20. Coativy G, Gautier N, Pontoire B, Buléon A, Lourdin D, Leroy E. Shape memory starch-clay bionanocomposites. Carbohydrate Polymers. 2015;116:307-313.

21. Chung YL, Lai HM. Preparation and properties of biodegradable starch-layered double hydroxide nanocomposites. Carbohydrate Polymers. 2010;80(2):525-532.

22. Lee S, Park M, Kim D, Kim I, Park D. Catalytic performance of ion-exchanged montmorillonite with quaternary ammonium salts for the glycerolysis of urea. Catalysis Today. 2014;232:127-133.

23. Romero-Bastida CA, Tapia-Blácido DR, Méndez-Montealvo G, Bello-Pérez LA, Velázquez G, Alvarez-Ramirez J. Effect of amylose content and nanoclay incorporation order in physicochemical properties of starch/montmorillonite composites. Carbohydrate Polymers. 2016;152:351-360.

24. Casariego A, Sousa BWS, Cerqueira MA, Teixeira JA, Cruz L, Díaz R, et al. Chitosan/clay films' properties as affected by biopolymer and clay micro/nanoparticles' concentrations. Food Hydrocolloids. 2009;23(7):1895-1902.

25. Choudalakis G, Gotsis AD. Permeability of polymer/clay nanocomposites: A review. European Polymer Journal. 2009;45(4):967-984.

26. Tan B, Thomas NL. A review of the water barrier properties of polymer/clay and polymer/graphene nanocomposites. Journal of Membrane Science. 2016;514:595-612.

27. Matsuda DKM, Verceheze AES, Carvalho GM, Yamashita F, Mali S. Baked foams of cassava starch and organically modified nanoclays. Industrial Crops and Products. 2013;44:705-711.

28. Majdzadeh-Ardakani K, Navarchian AH, Sadeghi F. Optimization of mechanical properties of thermoplastic starch/clay nanocomposites. Carbohydrate Polymers. 2010;79(3):547-554.

29. Romero-Bastida CA, Bello-Pérez LA, Velazquez G, AlvarezRamirez J. Effect of the addition order and amylose content on mechanical, barrier and structural properties of films made with starch and montmorillonite. Carbohydrate Polymers. 2015;127:195-201.

30. Valodkar M, Thakore S. Organically modified nanosized starch derivatives as excellent reinforcing agents for bionanocomposites. Carbohydrate Polymers. 2011;86(3):1244-1251. 